\title{
Effects of Habitat-Specific Primary Production on Fish Size, Biomass, and Production in Northern Oligotrophic Lakes
}

\author{
Sven Norman, ${ }^{1 *}$ Karin A. Nilsson, ${ }^{1,2}$ Marcus Klaus, ${ }^{3}$ David Seekell, ${ }^{1}$ \\ Jan Karlsson, ${ }^{1}$ and Pär Byström ${ }^{1}$
}

\begin{abstract}
${ }^{1}$ Department of Ecology and Environmental Sciences (EMG), Climate Impacts Research Center (CIRC), Umeå University, 90187 Umeå, Sweden; ${ }^{2}$ Department of Wildlife, Fish and Environmental Studies, SLU, 90183 Umea, Sweden; ${ }^{3}$ Department of Forest Ecology and Management, SLU, 90183 Umeå, Sweden
\end{abstract}

\begin{abstract}
Ecological theory predicts that the relative distribution of primary production across habitats influence fish size structure and biomass production. In this study, we assessed individual, population, and community-level consequences for brown trout (Salmo trutta) and Arctic char (Salvelinus alpinus) of variation in estimated habitat specific (benthic and pelagic) and total whole lake ( $\left.\mathrm{GPP}_{\text {whole }}\right)$ gross primary production in 27 northern oligotrophic lakes. We found that higher contribution of benthic primary production to $\mathrm{GPP}_{\text {whole }}$ was associated with higher community biomass and larger maximum and mean sizes of fish. At the population level, species-specific responses differed. Increased benthic primary production $\left(\mathrm{GPP}_{\text {Benthic }}\right)$ correlated to higher population biomass of brown trout regardless of being alone or in sympatry, while Arctic char responded positively to pelagic primary production
\end{abstract}

Received 29 April 2021; accepted 7 December 2021; published online 12 January 2022

Supplementary Information: The online version contains supplementary material available at https://doi.org/10.1007/s10021-021-0073 3-6.

Author contributions SN collected field data and conducted laboratory analysis. MK performed GPP estimations. SN and KN performed habitat specific modeling and analyses. PB and JK with additional input from SN and DS conceived the study. SN and PB drafted the manuscript. All authors contributed to manuscript edits.

*Corresponding author; e-mail: sven.norman84@gmail.com
$\left(\mathrm{GPP}_{\text {Pelagic }}\right)$ in sympatric populations. In sympatric lakes, the maximum size of both species was positively related to both $\mathrm{GPP}_{\text {Benthic }}$ and the benthic contribution to $\mathrm{GPP}_{\text {whole. }}$ In allopatric lakes, brown trout mean and maximum size and Arctic char mean size were positively related to the benthic proportion of GPP Whole. $_{\text {Our results highlight the importance of }}$ light-controlled benthic primary production for fish biomass production in oligotrophic northern lakes. Our results further suggest that consequences of ontogenetic asymmetry and niche shifts may cause the distribution of primary production across habitats to be more important than the total ecosystem primary production for fish size, population biomass, and production. Awareness of the relationships between light availability and asymmetric resource production favoring large fish and fish production may allow for cost-efficient and more informed management actions in northern oligotrophic lakes.

Keywords; Ontogenetic asymmetry; Lake productivity; Benthic primary production; Pelagic primary production; Arctic char; Brown trout. 


\section{HighLights}

- Ontogenetic development and asymmetric resource availability impact fish production

- Lake fish production, biomass and size vary with habitat-specific primary production

- Light climate in lakes can be used as a proxy for fish biomass, production and size.

\section{INTRODUCTION}

The productivity of northern lakes has been suggested to be mainly controlled by light-limited primary production in benthic habitats (Vander Zanden and Vadeboncoeur 2002; Karlsson and Byström 2005; Karlsson and others 2009). In those lakes, benthic algae provide the main energy source for the benthic invertebrate community, which is a major resource for many fish species (Vander Zanden and Vadeboncoeur 2002; Karlsson and others 2009; Vander Zanden and others 2011). However, most fish species undergo ontogenetic niche shifts during growth, for example, from feeding on small-sized zooplankton to larger invertebrates, highlighting the potential importance of the pelagic resource production for juvenile fish growth and survival (Werner and Gilliam 1984; Persson and Greenberg 1990; Jansen and others 2003). The spatial distribution of total resource production for many fish species can therefore be conceptualized as two distinct zones, one where the juvenile resource is mainly produced in the pelagic habitat and the other where benthic habitat provides resources mainly for adults.

Besides the basal productivity of an ecosystem, the relative resource production between two habitats has been suggested to have a major influence on fish production and population biomass (de Roos and Persson 2013; Persson and de Roos 2013; Reichstein and others 2015). This is because fish production and biomass depend on which ontogenetic stage, juvenile or adult, is most resource limited (de Roos and Persson 2013). Small individuals generally have an exploitative competitive advantage over large, as they can avoid starvation and maintain growth on lower resource levels as compared to larger conspecifics (Persson 1985; Lundberg and Persson 1993; Werner 1994; Persson and others 1998; Aljetlawi and Leonardsson 2002; Byström and Andersson 2005). Considering the case where superior juveniles compete with adults for a single shared resource-juveniles grow fast and mature early, but as they reach larger sizes, resource limitation increases, which leads to slower growth and a population that is dominated by high densities of slow-growing and small adults (Persson and de Roos 2013). In such 'stunted' populations, adult biomass production and reproduction is low because growth and fecundity are strongly constrained by resource availability and the biomass production is limited by a bottleneck in reproduction. However, in the presence of ontogenetic niche shifts, this competitive advantage of juveniles can be relaxed or offset by a high production of resources (that is, large-sized prey) that are more exclusive to larger-sized adult fish (Persson and de Roos 2013). In support for such a consequence of ontogenetic niche shifts, Reichstein and others (2015) experimentally showed that a reallocation of resource supply from the juvenile stage to the competitively inferior adult stage resulted in higher reproduction and total population biomass even though the total level of resource supply remained constant. The same qualitative response is expected from an increased resource supply to adults while juvenile resource supply is held constant, but with an even higher response in total biomass (de Roos and Persson 2013; Reichstein and others 2015). Transferring the above rationale developed foremost in de Roos and Persson (2013) and experimentally confirmed by Reichstein and others (2015) to present understanding of northern mountain lakes, we hypothesize that the relative resource production between pelagic and benthic habitats and absolute levels of benthic production determine patterns of mountain fish population demographics and production.

High-altitude lakes in northern Europe are dominated by relatively small clear water lakes but with high variability in lake depth, which implies large variations in pelagic and benthic habitat availability (Downing 2014; Seekell and others 2021). The fish communities in these lakes have low species richness and typically consist of allopatric or sympatric populations of Arctic char (Salvelinus alpinus) and brown trout (Salmo trutta) (Figure 1A). Zooplankton and benthic invertebrates are the main resources for both species, and their relative contribution to the diets commonly depend on fish size (Forseth and others 1994; Hesthagen and others 1997; Amundsen and others 2003; Saksgård and Hesthagen 2004; Eloranta and others 2010). Arctic char is generally a more efficient planktivore than brown trout, whereas brown trout is a more efficient benthivore (Langeland and others 1991; Hesthagen and others 1997; Saksgård 


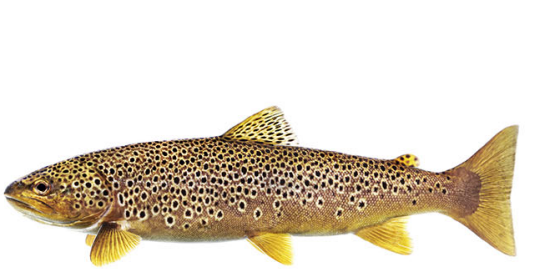

Brown trout (Salmo trutta)

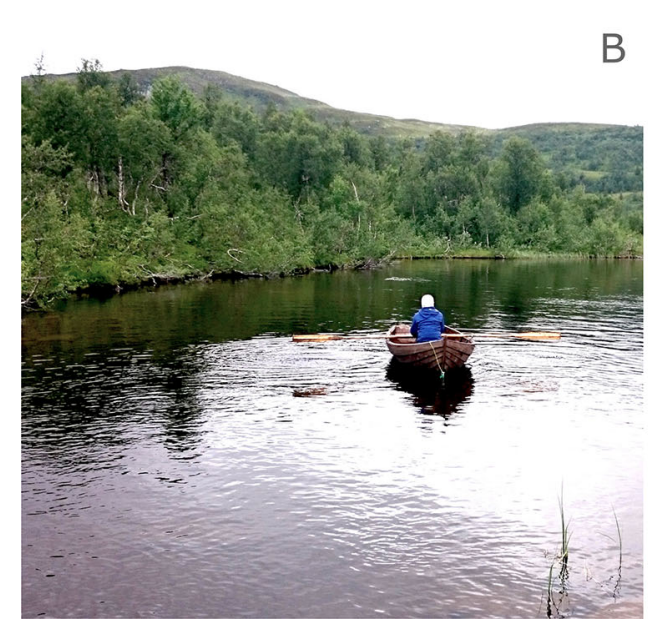

A

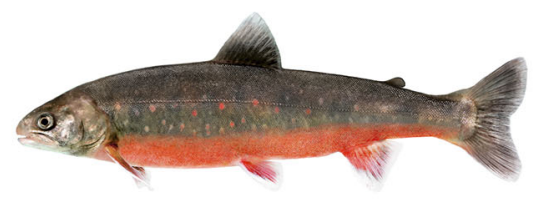

Arctic char (Salvelinus alpinus)

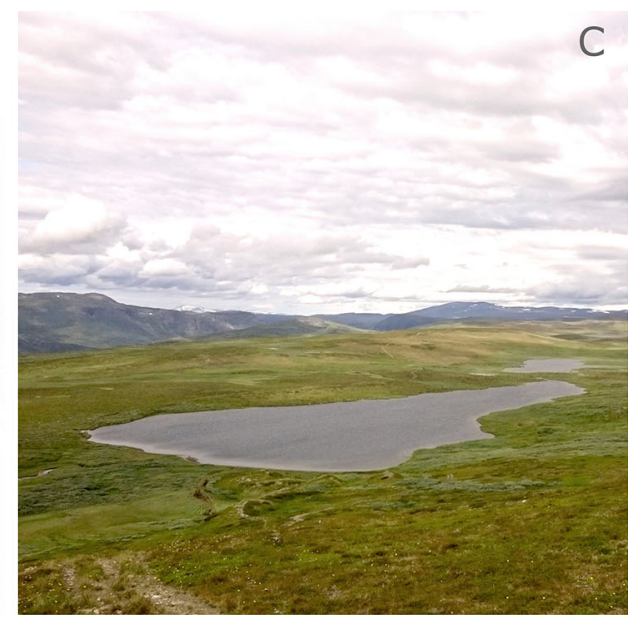

Figure 1. Panel A depicts the two fish species that are found in the lakes either alone or in sympatry. Panel B depicts one of the vegetation extremes, birch forest (ZF07, 649 m.a.s.l.). Panel C depicts the other vegetation extreme in our data set (AC01, 875 m.a.s.l.) with dry heath, sparsely populated by rock fields. Photo: Jörgen Wiklund (A) and Sven Norman (B and $\mathrm{C}$ ).

and Hesthagen 2004). Population size structures in these mountain lakes, even at local scales, range from domination by stunted small-sized adults to a domination by fast-growing large adults, and even bimodal size distributions due to the presence of large cannibals (Klemetsen and others 2003) or piscivores as suggested by Sánchez-Hernández (2020). This variation in population size structures among lakes suggests that the intensity and outcome of size-dependent competition is sensitive to lake-specific environmental conditions. The large variation in pelagic and benthic habitat availability among lakes further suggests that the variation in primary production between these two habitats may potentially explain the range in population size structure and fish production among these lake ecosystems.

In this study, we estimated population size structure (maximum and mean length), biomass, and yearly production of Arctic char and brown trout in mountain lakes in northern Sweden and tested if they were correlated to measures of light climate, whole ecosystem primary production, and/ or habitat-specific primary production. In addition, we also tested if temperature and lake-specific morphological characteristics explained our variation in measured response variables. Our main hypotheses were (1) that biomass and production of fish would be more dependent on benthic primary production $\left(\mathrm{GPP}_{\text {Benthic }}\right)$ than on whole-lake (benthic and pelagic) primary production $\left(\mathrm{GPP}_{\text {Whole }}\right)$ or pelagic primary production $\left(\mathrm{GPP}_{\text {Pelagic }}\right),(2)$ that the biomass and production of fish to depend on the relative production of resources to juveniles and adults, where a higher benthic proportion of $\mathrm{GPP}_{\text {Whole }}$ will result in larger fish and higher total biomass, and (3) that brown trout (more efficient benthivore) shows stronger responses to variation in $\mathrm{GPP}_{\text {Benthic }}$ compared to Arctic char (more efficient planktivore), while Arctic char show stronger response to variation in $\mathrm{GPP}_{\text {Pelagic. }}$

\section{MethodS}

We evaluated habitat-specific primary production as a predictor of fish production, standing stock biomass, and population size structure in 27 small lakes ranging in size from 4 to 40 hectares and in water clarity $\left(k_{\mathrm{d}}\right)$ from $0.19 \mathrm{~m}^{-1}$ (very clear) to $1.47 \mathrm{~m}^{-1}$ (intermediately brown colored) situated 
in or near the alpine region of Sweden (Appendix, Table Al). They represent the range of variations among small oligotrophic lakes in this region, mostly differing in lake depth and catchment size. The catchment vegetation types range with altitude from birch forests at lower elevations (Figure 1B) to dry heath above the tree line (that is, at intermediate elevations) and to low vegetation open rock fields with sparse dry heath patches at higher elevations (Figure 1C). Ten of the lakes contained both species of fish (Figure 1A) (sympatric) and 17 had either Arctic char $(N=5)$ or brown trout $(N=12)$ (allopatric). The range of the measured physiochemical variables are summarized in Table 1 .

\section{Fish Biomass and Size Structure}

The sampling of fish was done using gillnets. We obtained a measure of lake-specific fish biomass using the commonly used index catch per unit of effort (CPUE) which provides a relative estimate of fish biomass and abundance among lakes. We chose to describe fish biomass in CPUE units for three reasons, (1) it is a widely used metric of relative fish biomass and production (for example, Kahilainen and Lehtonen 2002; Karlsson and others 2009; Eloranta and others 2013; Svenning and others 2015; Craig and others 2017; Vainikka and others 2017; Morrissey-McCaffrey and others 2018), (2) it is cost-effective which enabled an adequate sample size in a logistically challenging mountain region, and (3) it is the standard approach within Sweden (Swedish-standards-institute 2015) and the EU which therefore facilitates comparisons with governmental test fishing databases and monitoring data. The gillnetting was done in August 2016 and 2017, in accordance with the Swedish standard survey gillnetting method (Swedish-standards-institute 2015) with Nordic 12 standard survey multi-mesh gillnet $(30 \times 1.5 \mathrm{~m})$, with sections of mesh sizes of $5,6.25,8,10,12.5$, $15.5,19.5,24,29,35,43$, and $55 \mathrm{~mm}$. The number of nets used per lake depended on lake area and maximum depth and was set randomly within each depth zone (0-3, 3-6, 6-12, 12-20, and $20 \mathrm{~m}$ ) (see Appendix Figure A3). The proportion of nets allocated to each depth zone was decided by the areal proportion of that depth zone to the whole lake area. The nets were set in the afternoon and emptied the following morning so that the two periods of high fish activity, dusk and dawn, were included (Westin and Aneer 1987). CPUE was calculated for each depth zone as $\mathrm{g} \mathrm{net}^{-1}$. A lakespecific CPUE was then calculated as the average catch per net among the depth zones weighted by the contribution to total lake area of each respective depth zone. As such, the obtained CPUE estimate reflects a relative measure of lake fish biomass per surface area. Further, we evaluated the sensitivity of the obtained CPUE estimate to this weighting by recalculating CPUE weighted by volume above each depth zone. The results were indistinguishable from the CPUE weighted by areal proportion (Pearson correlation $r=1, p<0.01$ ). Consequently, we used our proportional depthdependent surface area corrected CPUE as a density-related estimate of fish biomass in our analysis.

All captured fish were deep-frozen separately per gillnet for later analysis. Fish length and weight were measured in the laboratory and the otoliths of a size representative subsample $(n=30)$ of each population were removed (on all fish if less than 30 were captured) for age determination and subsequent growth and production estimates. Otolith

Table 1. Range of Physical and Nutrient Parameters in the Sampled Lakes

\begin{tabular}{lcc}
\hline Parameter & Median & Range \\
\hline Mean depth $(\mathrm{m})$ & 3.5 & $0.5-10.9$ \\
Max depth $(\mathrm{m})$ & 10.8 & $2.2-31.2$ \\
Area (hectare) & 9.75 & $4-40$ \\
Light climate $\left(I_{\mathrm{m}}\right)$ & 0.38 & $0.19-0.89$ \\
Light attenuation coefficient $\left(K_{\mathrm{d}}, \mathrm{m}^{-1}\right)$ & 0.64 & $0.19-1.47$ \\
Temperature $\left({ }^{\circ} \mathrm{C}\right)$ & 8.8 & $7.35-10.93$ \\
DOC $\left(\mathrm{mg} \mathrm{L}^{-1}\right)$ & 2.95 & $0.46-7.52$ \\
TDN $\left(\mu \mathrm{g} \mathrm{L}^{-1}\right)$ & 101.6 & $32.7-189.2$ \\
TN $\left(\mu \mathrm{g} \mathrm{L}^{-1}\right)$ & 134.5 & $67.8-199.3$ \\
TP $\left(\mu \mathrm{g} \mathrm{L}^{-1}\right)$ & 4.8 & $3.72-8.06$
\end{tabular}

The temperature, DOC and nutrient parameters are the average over the open water season. Detailed per lake descriptions of these parameters are provided in Appendix, Table Al. 
readings were done under a microscope with the otoliths submerged in glycerol to improve the contrast between the annual rings. The lack of an asymptote in length and age relationships in most lakes made growth parameter estimates based on von Bertalanffy curves unattainable. For methodological consistency, we fitted linear, power, and sigmoidal models describing age at length and weight at length in each lake and used the Akaike information criterion corrected for small sample sizes to select the best model for each lake. There was little difference in the model fits across the ranges of length and age in our study, and model uncertainty is unlikely to have any impact on our analyses (Appendix, Figure A6 and A7). Using the selected models, we then estimated the average lake specific weight of a $150 \mathrm{~mm}$ (small) and $300 \mathrm{~mm}$ (large) fish, and then estimated the weight of these at year +1 using the selected model to establish the specific growth rate of small and large fish, respectively, as:

Specific growth rate $=\left(\ln \left(W_{t+1}\right)-\ln \left(W_{t}\right)\right) \times 100$

where $W$ is the fish weight at time $t$ and $t+1$ (year). To estimate the yearly fish production we summed up the estimated yearly growth of each captured individual based on individual length and estimated yearly weight increase from the growth rate functions (Karlsson and others 2009).

\section{Physical and Chemical Parameters}

Lake bathymetry was determined from integrated GPS and echo-sounding depth measurements (transects were roughly $10-15 \mathrm{~m}$ apart). We measured lake physical and chemical parameters (Table 1) either continuously (surface light and air temperature) or at approximately monthly intervals [dissolved organic carbon (DOC), total phosphorus (TP), total nitrogen (TN), and photosynthetically active radiation (PAR)] during the ice-free period. Air temperature was measured every $10 \mathrm{~s}$ and logged every 10 min using HOBO U30-NRC weather stations installed $1.9-2.5 \mathrm{~m}$ above ground. Oxygen loggers were deployed near the surface and near the bottom (see below and Appendix for detailed methodology for use in the free-water diel oxygen technique for determining GPP). Due to the remoteness of four lakes (ZFOl, ZF05, ZF06, and ZF07, see Table Al in Appendix) we could not set up weather stations to measure air temperature. Modeled grid data $\left(4 \mathrm{~km}^{2}\right)$ was instead acquired and corrected for elevation, for these lakes from the Swedish Meteorological and Hydrological Institute, (SMHI), https://www.smhi. se/data/meteorologi/temperatur, accessed: 201904-08).

A composite water sample (at 1, 2, 4, 8, 16 m or down to value closest to maximum depth) for chemical parameters was taken at the deepest point of the lake on each sampling occasion. For DOC, water was passed through a preignited $\left(400{ }^{\circ} \mathrm{C}\right.$ for $3 \mathrm{~h}$ ) Whatman GF/F filter, and the filtrate was acidified and stored cold before analysis. DOC was analyzed with an IL550 TOC/TDN analyzer (HachLange $\mathrm{GmbH}$, Dusseldorf, Germany). PAR was measured every $0.5 \mathrm{~m}$ of the water column using a LI-193 spherical quantum sensor (LI-COR Biosciences, Lincoln, Nebraska, USA). TN and TP were analyzed according to methods described in Bergström and others (2013).

The mean light climate $\left(I_{\mathrm{m}}\right)$ of the whole lake volume, expressed as a fraction of light entering the lake, was calculated as described in Karlsson and others (2009):

$$
I_{\mathrm{m}}=\left(1-e^{-k_{\mathrm{d}} \times Z_{\mathrm{m}}}\right) /\left(k_{\mathrm{d}} \times Z_{\mathrm{m}}\right)
$$

where $k_{\mathrm{d}}$ is the vertical light attenuation coefficient and $Z_{\mathrm{m}}$ is the mean depth. Low values (close to 0 ) of $I_{\mathrm{m}}$ represent lakes that are either very deep and/ or very colored, while high values (close to 1 ) describe shallow and/or very clear lakes.

\section{Gross Primary Production and Habitat- Specific Proportion}

We estimated gross primary production ( $\mathrm{GPP}_{\text {whole }}$ ) for the whole lake volume, including both pelagic and benthic GPP, using the free-water diel oxygen technique (Staehr and others 2010). We used an inverse modeling approach to describe the daily fluctuations in dissolved oxygen concentrations measured at a given depth. For each day, the model solves for the most likely values of gross primary production and ecosystem respiration, minimizing the difference between modeled and measured oxygen concentrations. The model scales gross primary production by incoming light and ecosystem respiration by water temperature and also accounts for atmospheric gas exchange. To yield $G_{\text {GP }}$ whole we integrated daily depth-specific estimates of gross primary production over the whole lake volume and sampling season weighted by estimated model uncertainty for specific days (for further details, see Appendix). GPP whole therefore represents the estimated gross primary production in the whole lake over the entire season expressed per liter and day which is common practice using the free-water diel oxygen technique (Hanson and others 2008; Staehr and others 2010; Solomon and 
others 2013). Thus, both our estimates of GPP and CPUE are standardized by lake size which ensures their analytical compatibility.

The free-water diel oxygen technique incorporates both pelagic and benthic GPP but cannot differentiate between them. The habitat-specific contributions to estimated GPP $\mathrm{Phole}_{\text {were }}$ werefore calculated using a modified version of the primary production model by Vadeboncoeur and others (2008) named the autotrophic structure model in Devlin and others (2016) also used in Vander Zanden and others (2011) to estimate benthic contribution to whole lake primary production. The model accounts here for the measured lake morphometry, light attenuation in the water column, and predefined maximum productivity of algae in different habitats and results in estimates of epipelic, epilithic (benthic algae), and phytoplankton GPP. The maximum productivity (parameters $\mathrm{BPmax}_{\mathrm{s}}$ and PPmax, Appendix Table A3) that we used in our model runs was obtained from studies in four lakes where benthic and pelagic production had been measured in detail at multiple depths (Ask and others 2009). These lakes can be considered representative of our study lakes in terms of size, nutrient status, and surrounding vegetation (see Appendix, Table A3 for parameterization and further details). Because the autotrophic structure model does not account for between-lake differences in factors such as seasonal temperature development that may have effects on the magnitude of primary production $\left(\mathrm{O}^{\prime}\right.$ Connor and others 2009; Hamdan and others 2021), we only used the model results to obtain an estimate of the relative contribution of habitat-specific production to $\mathrm{GPP}_{\text {whole. }}$ We applied the benthic proportion of GPP from the autotrophic structure model to the

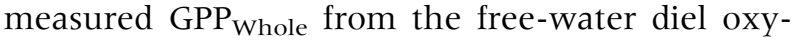
gen technique to estimate the habitat specific production (GPP Pelagic $\left._{\text {and }} \mathrm{GPP}_{\text {Benthic }}\right)$. The rationale for combining the methods for habitat-specific estimations is that the free-water diel oxygen technique uses in situ measures of $\mathrm{GPP}_{\text {Whole }}$ that incorporate habitat specific productivities and lake specific environmental conditions (for example, temperature) that are not included in the modeled estimates.

\section{Statistics}

All data handling and statistical tests were done using R (R Core Team 2021). The R-packages that we used are listed in Appendix (Table A9). We analyzed fish biomass and production and its relation to whole-lake and habitat-specific GPP, light climate, and the benthic proportion of $\mathrm{GPP}_{\text {Whole }}$ using linear regression models. At the fish community level, we first ran linear mixed-effects models with the main explanatory variables (whole-lake and habitat-specific GPP, light climate, and the benthic proportion of $\mathrm{GPP}_{\text {whole }}$ ) as fixed factors and included temperature as a random factor to account for possible climate influences on our response variables. None of the models that included temperature was significantly better than models with only the main explanatory variable (ANOVA: $p>0.05$ in all cases). For species-level data, the relatively low sample size did not allow us to test for the influence of temperature on the main explanatory variables. We therefore excluded temperature as a random effect from all statistical models and report only results from our univariate linear model runs (Table 3). We are not able to discern effects of air temperature on habitat-specific GPP estimates because a potential temperature effect in any of the habitats would be included in the $\mathrm{GPP}_{\text {whole }}$ measurement, and our modeling approach would therefore misallocate the effect onto both habitats according to their respective contribution to GPP Whole

We tested for community and species-specific differences in mean and maximum fish size using a one-way ANOVA and Tukey's post hoc test for differences between the groups. We further analyzed the effects of the benthic proportion of $\mathrm{GPP}_{\text {Whole, }}$ temperature, and lake type (allopatric and sympatric populations) on growth variables (specific growth rates and ratio of specific growth rates of small and large fish). The explanatory variables used in each model were chosen based on Akaike information criterion. The results from the best models are presented in the results section. (The retained variables are listed in Appendix, Table A4.)

Table 2. $P$-values of Regression Coefficients and Direction of Effects (Positive/Negative Sign) from Univariate Regression Models of GPP (Total and by Habitat) as Functions of Physiochemical Factors

\begin{tabular}{lccc}
\hline & GPP $_{\text {whole }}$ & GPP $_{\text {pelagic }}$ & GPP $_{\text {benthic }}$ \\
\hline$I_{\mathrm{m}}$ & $<\mathbf{0 . 0 1}+$ & 0.38 & $<\mathbf{0 . 0 1}$ \\
$\mathrm{DOC}$ & 0.42 & $<\mathbf{0 . 0 1}+$ \\
$\mathrm{TN}$ & 0.71 & $<\mathbf{0 . 0 1}+$ & 0.31 \\
$\mathrm{TP}$ & 0.27 & 0.47 & 0.59 \\
& & & 0.24
\end{tabular}

Significant correlations at $p<0.05$ are highlighted in bold. Detailed regression model summaries are given in Appendix, Table A5. 


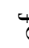


$I_{\mathrm{m}}$ is by definition correlated to mean lake depth and $k_{\mathrm{d}}$ and we therefore only used $I_{\mathrm{m}}$ as explanatory variable for light effects on our GPP measures. In addition, $I_{\mathrm{m}}$ and the benthic proportion of $\mathrm{GPP}_{\text {Whole }}$ are naturally collinear (in our data set $\left(r^{2}=0.77\right)$ as they both depend on lake depth and the vertical light attenuation through the water column. However, we retain both, because $I_{\mathrm{m}}$ has previously been used to describe patterns of fish production in lakes where it is implicitly assumed to be a proxy for primary production (Karlsson and others 2009; Seekell and others 2015) while the benthic proportion of $\mathrm{GPP}_{\text {whole }}$ is the relevant measure to quantify the effects of ontogenetic asymmetry and habitat-specific resource production for fish population size structure and biomass (Reichstein and others 2015). Allopatric fish populations are functionally different from multispecies fish communities as intra- and interspecific competition and predation/cannibalism are likely to differ in strength and importance. Therefore, we analyze correlations for all types of fish communities, that is, allopatric or sympatric of either species as well as the combined whole community (allopatric and sympatric) (see Table 3 ).

\section{Ethical Considerations}

The sampling and sacrifice of fish in this study were done in accordance with current laws of Sweden and approved by the local ethics committee of the Swedish National Board for Laboratory Animals in Umeå (CFN, license no. A-20-2014 to Pär Byström).

\section{ReSUlts}

\section{Primary Production}

The benthic proportion of $\mathrm{GPP}_{\text {whole }}$ was high, ranging from 79 to $95 \%$, and was positively correlated to light climate $\left(I_{\mathrm{m}}\right)$ (OLS regression on logit-transformed benthic proportion as a function of $I_{\mathrm{m}}, F(1,25), p<0.01$, adjusted $R^{2}=0.82$, Figure 2). The benthic proportion of GPP whole was positively correlated to $\mathrm{GPP}_{\text {whole }}$ (Pearson, $r=0.77, p<0.01$ ). The benthic proportion of GPP was not correlated to lake volume (Pearson, $r-$ $0.19, p=0.33)$. $\mathrm{GPP}_{\text {whole }}$ and $\mathrm{GPP}_{\text {Benthic }}$ were positively related to $I_{\mathrm{m}}$ (Table 2 ). GPP Pelagic was positively related to the light attenuation coefficient $\left(k_{\mathrm{d}}\right)$ (Pearson, $r=0.72, p<0.01$ ) and $k_{\mathrm{d}}$ was positively correlated to DOC concentration (Pearson, $r=0.95, p<0.01)$. GPP Benthic was negatively related to average depth of the lakes (Pearson, $r=-0.67, p<0.01$ ), while no correlation was
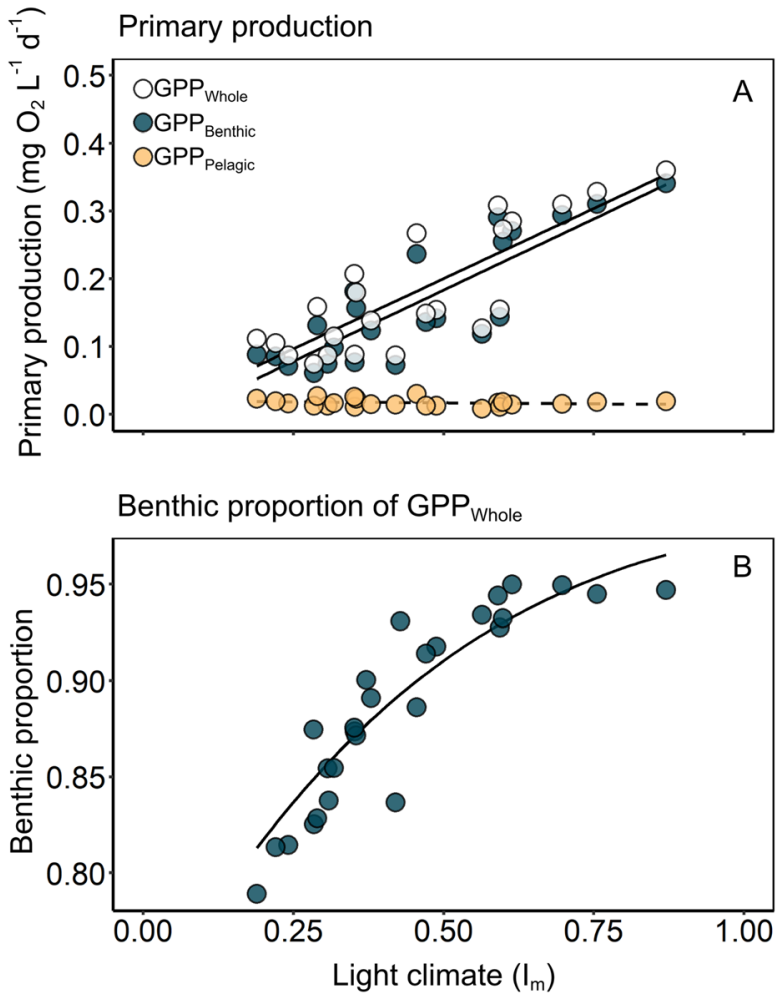

Figure 2. A Whole lake primary production $\left(\mathrm{GPP}_{\text {Whole }}\right)$ and the estimated contribution to $\left(\mathrm{GPP}_{\text {whole }}\right)$ from the pelagic $\left(\mathrm{GPP}_{\text {Pelagic }}\right)$ and benthic $\left(\mathrm{GPP}_{\text {Benthic }}\right)$ habitat. B The benthic proportion of GPP ${ }_{\text {whole }}$ as a function of light climate $\left(I_{\mathrm{m}}\right)$. Solid lines denote significant correlations $(p<0.05)$. The solid line in panel $\mathrm{B}$ is the backtransformed prediction from a regression model describing the logit-transformed benthic proportion of $\mathrm{GPP}_{\text {Whole }}$ as a function of $I_{\mathrm{m}}$.

found with $k_{\mathrm{d}}$ nor DOC concentration. Average air temperature over the season did not correlate with $\operatorname{GPP}_{\text {Whole }}(p>0.05)$, while relationships between GPP estimates and nutrients were only found for $\mathrm{GPP}_{\text {Pelagic }}$ which was positively correlated with TN and DOC (Table 2).

\section{Fish Biomass and Production}

Total fish biomass and production were not signif-

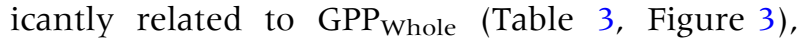
habitat-specific GPP, or air temperature (although there was a tendency to a positive relationship, $p=0.06-0.09$ (GPP Whole $)$, Table 3). Instead, fish biomass and production increased with increasing $I_{m}$ and the benthic proportion of GPP whole (Table 3, Figure 3B). Air temperature did not affect total fish biomass and production (Table 3).

The biomass of brown trout increased with increasing GPP whole and $\mathrm{GPP}_{\text {Benthic }}$ in both allopatric and sympatric populations (Figure 4), whereas 


\section{Fish community biomass \& production}
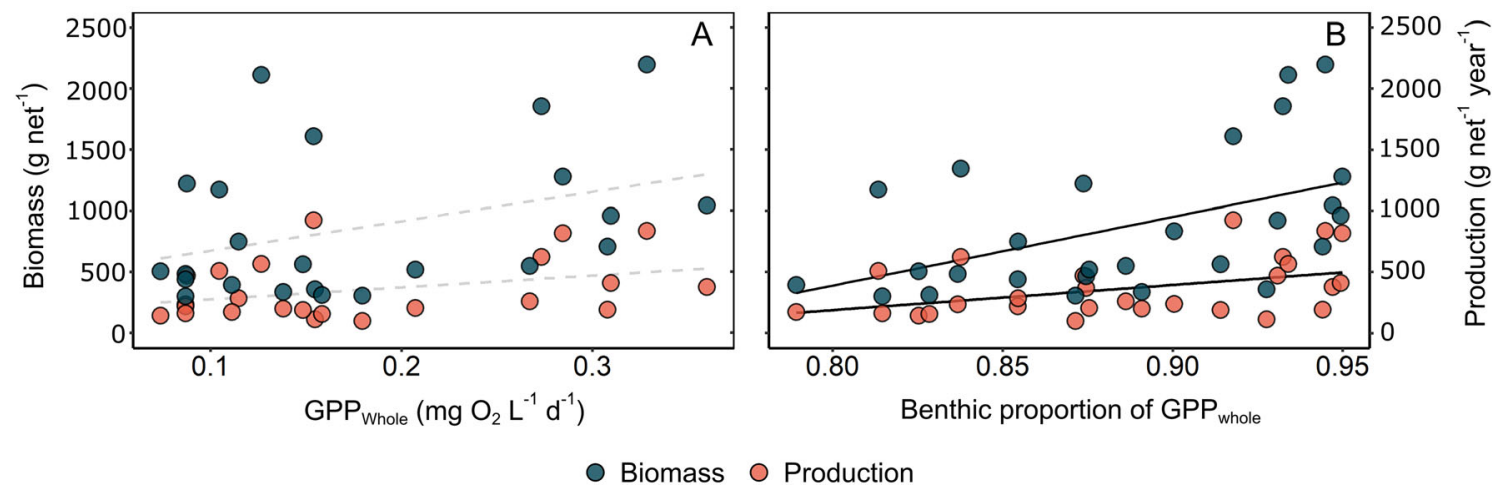

Figure 3. A Fish community biomass and production as a function of whole lake primary production (GPP $\left.\mathrm{Fhole}_{\mathrm{W}}\right)$ and $\mathbf{B}$ fish community biomass and production as a function of the benthic proportion of GPP whole. Solid lines denote significant correlations $(p<0.05)$, and dashed lines describe nonsignificant trends $(p>0.05)$.

the production of brown trout only increased in allopatric lakes with both increasing $\mathrm{GPP}_{\text {whole }}$ and GPP $_{\text {Benthic }}$ (Table 3). The biomass of brown trout increased with increasing $I_{\mathrm{m}}$ in both allopatric and sympatric populations (Table 3). The biomass and production of sympatric Arctic char populations increased with increasing temperature as well as $\mathrm{GPP}_{\text {Pelagic }}$ (Table 3, biomass: Figure 4B).

\section{Population Size Structure and Growth}

The maximum length of brown trout increased with the benthic proportion of GPP whole in allopatric populations (Figure 5A) and increased for both species in sympatric populations (Figure 5B). Similarly, the mean length of both species in allopatric populations increased with the benthic proportion of $\mathrm{GPP}_{\text {whole }}$ (Figure 5C), whereas no
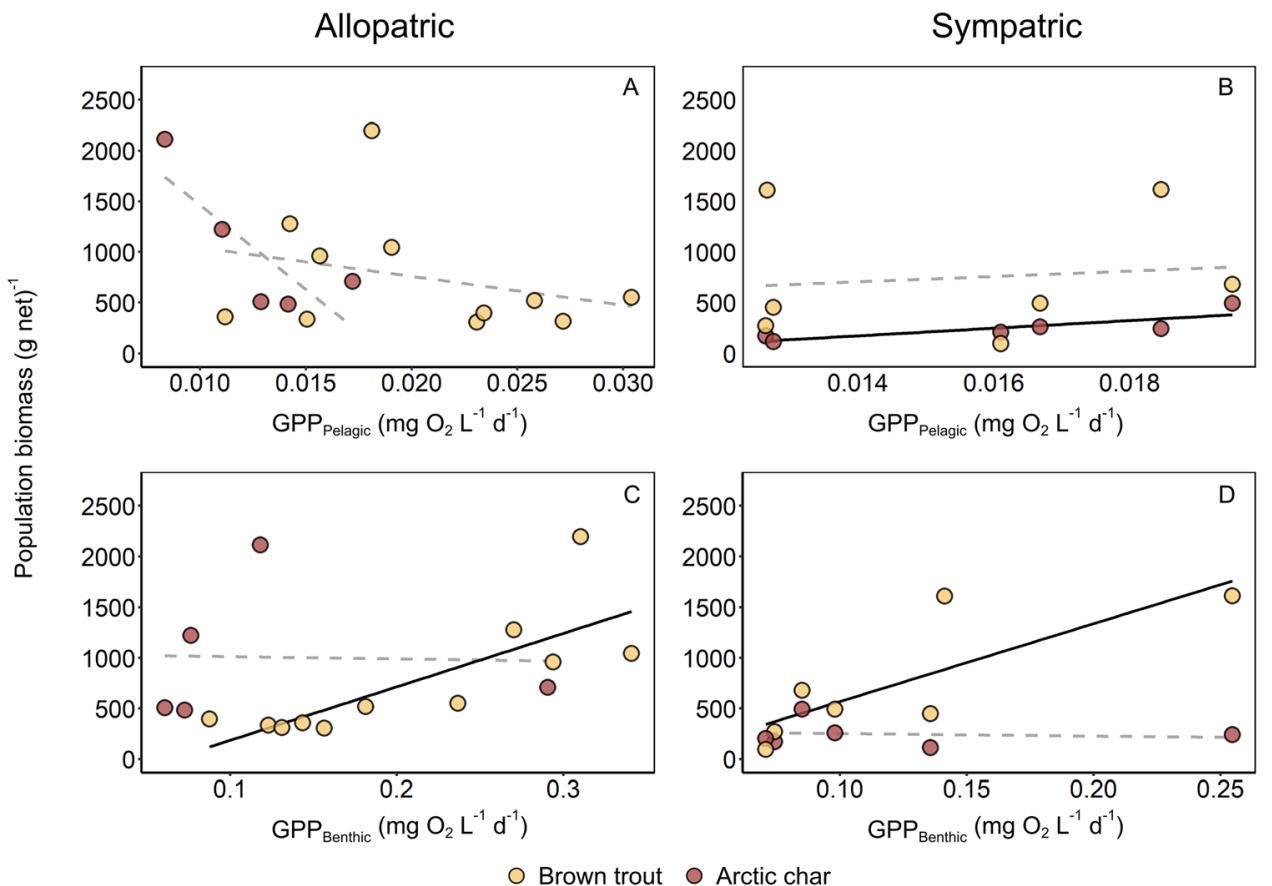

Figure 4. Fish population biomass in allopatric $(\mathbf{A}, \mathbf{C})$ and sympatric populations $(\mathbf{B}, \mathbf{D})$ as a function of $G P P_{\text {pelagic }}(\mathbf{A}, \mathbf{B})$ and $\mathrm{GPP}_{\text {Benthic }}(\mathbf{C}, \mathbf{D})$. Solid lines denote significant correlations $(p<0.05)$ and dashed lines describe nonsignificant trends $(p>0.05)$. Note that one data point for sympatric Arctic char is excluded from analysis and the figure because only one Arctic char was caught (AC08, see Appendix Table Al). 

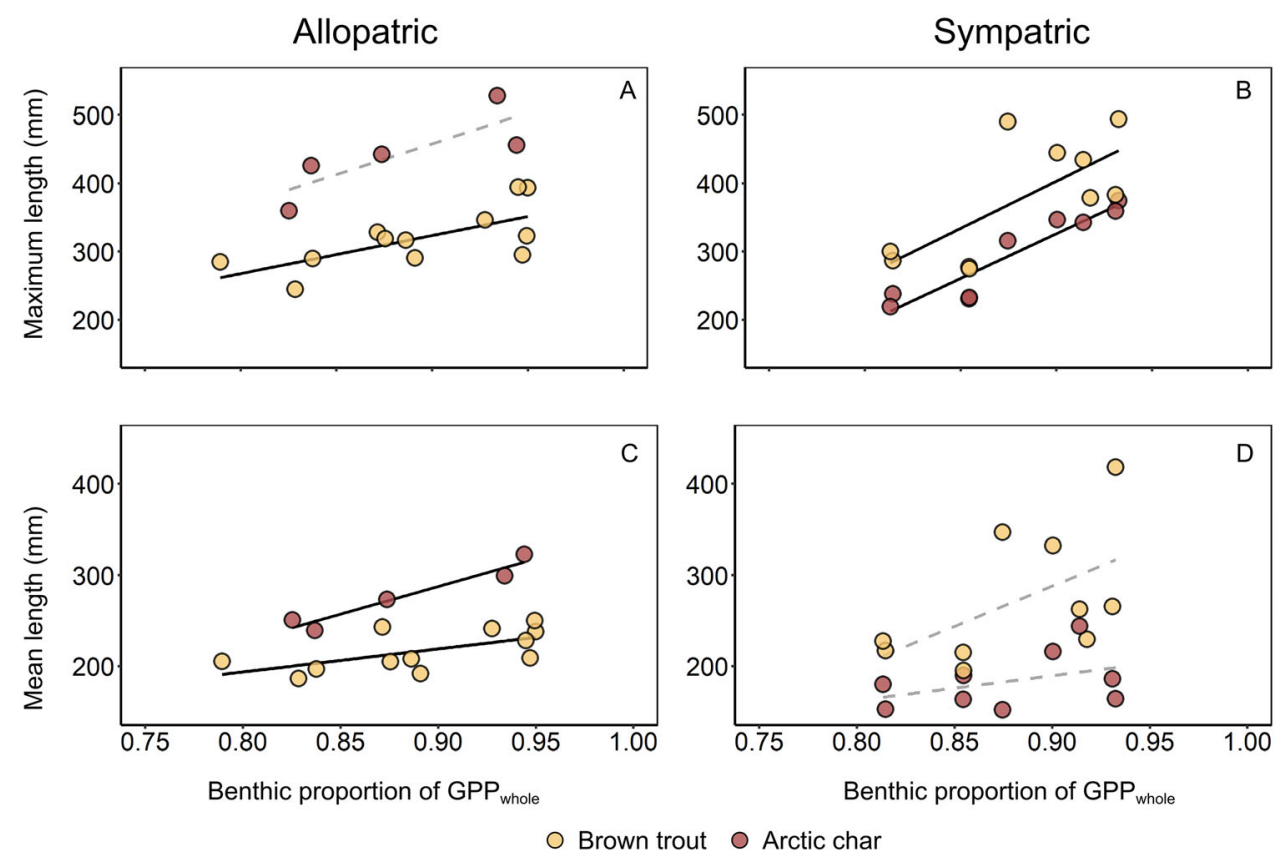

Figure 5. Fish maximum $(\mathbf{A}, \mathbf{B})$ and mean $(\mathbf{C}, \mathbf{D})$ length as a function of the benthic proportion of $\mathrm{GPP}_{\text {Whole }}$ in allopatric $(\mathbf{A}, \mathbf{C})$ and sympatric $(\mathbf{B}, \mathbf{D})$ populations. Solid lines denote significant correlations $(p<0.05)$, and dashed lines describe nonsignificant trends $(p>0.05)$. Note that one data point for sympatric Arctic char is missing because only one Arctic char was caught (AC08, see Appendix Table Al).

correlation could be found regarding mean lengths in sympatric populations (Figure 5D). In sympatric lakes, brown trout maximum and mean size (Pearson, max: $r=0.91, p<0.05$, mean: $r=0.94$, $p<0.01)$ as well as the maximum size of Arctic char increased with GPP Benthic (Pearson, $r=0.90$, $p<0.05)$. In allopatric populations, no correlations of max and mean length were found with the $\mathrm{GPP}_{\text {Benthic }}$ for either species. In addition, the mean and maximum lengths differ between the populations in allopatric and sympatric lakes (mean length-ANOVA: $f(3,32)=8.2, p<0.01$, maximum length-ANOVA: $f(3,32)=6.8, p<0.01$, Figure 5). Arctic char mean and maximum length were larger in allopatric populations relative to sympatric (Tukey: $p<0.01$ in both cases) and allopatric Arctic char maximum length was larger than that for allopatric brown trout (Tukey: $p<0.01)$. Brown trout mean length was larger than for Arctic char in sympatric lakes in (Tukey: $p<0.01$ ), while maximum length was close to significant (Tukey: $p=0.052$ ). Brown trout mean length was also larger in sympatric compared to allopatric populations (Tukey: $p<0.05$ ).

The specific growth rate of large brown trout (estimated for size $300 \mathrm{~mm}$ ) increased with the benthic proportion of GPP whole (linear regression model, $p=0.05, R^{2}=0.18$ ) while no relationships were present for small brown trout $(150 \mathrm{~mm})$ or in either of the size two size classes of Arctic char. The ratio of specific growth rates of large and small brown trout ( 300 and $150 \mathrm{~mm}$, respectively) increased with the benthic proportion of $\mathrm{GPP}_{\text {Whole }}$ (OLS linear regression model, $p=0.01, R^{2}=0.29$ ) while no correlation could be found for Arctic char (Figure 6). No relationships with temperature on

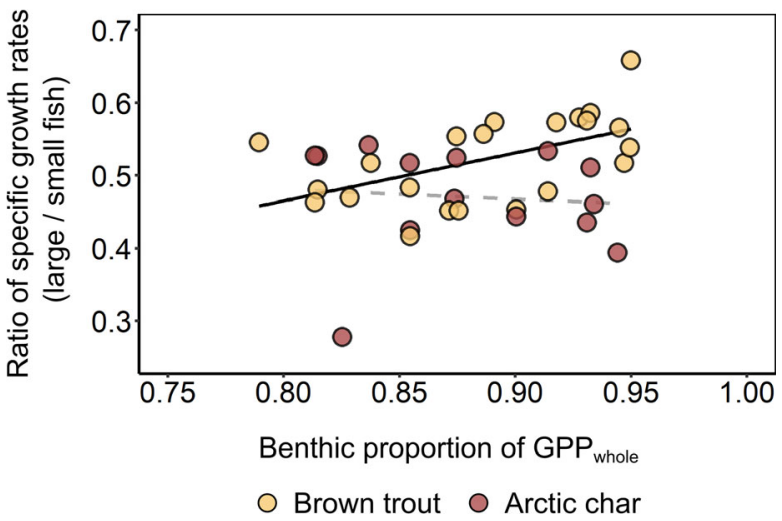

Figure 6 . The ratio of specific growth rates between small $(150 \mathrm{~mm})$ and large $(300 \mathrm{~mm})$ fish as a function of the benthic proportion of $\mathrm{GPP}_{\text {whole. The solid line }}$ denotes the significant correlation $(p<0.05)$ of brown trout, and the dashed line describes the nonsignificant trend $(p>0.05)$ for Arctic char. 
the above growth variables were present (Appendix, Table A4).

\section{Discussion}

The productivity of oligotrophic northern lakes depends strongly on light-controlled benthic primary production (Vander Zanden and Vadeboncoeur 2002; Karlsson and others 2009; Seekell and others 2015). In our study, benthic primary production $\left(\mathrm{GPP}_{\text {Benthic }}\right)$ accounted for $79-95 \%$ of the whole ecosystem primary production $\left(\mathrm{GPP}_{\text {whole }}\right)$ and was strongly dependent on the light climate $\left(I_{\mathrm{m}}\right)$ (Figure 2, Table 2), which is an integrated measure of light availability accounting for both light attenuation (water color) and lake depth. Correspondingly, we found that fish biomass and production measures were mainly controlled by $\mathrm{GPP}_{\text {Benthic }}$ (Figure 4, Table 3) and the benthic proportion of $\mathrm{GPP}_{\text {whole }}$ (Figure 3, Table 3). We found little evidence for any major temperature effects on GPP and fish community, population, and individual level responses, despite a relatively large latitudinal and altitudinal range and from a climate change relevant variation in temperature (Appendix, Table Al) among the lakes. In aquatic systems, primary production and consumer vital rates are strongly dependent on temperature, and temperature has been shown to impact fish individual growth, population size structure, and population biomass and production (Lindmark and others 2018; Huss and others 2019; van Dorst and others 2019). In our study, only air temperature was correlated with the production of sympatric Arctic char while no other significant associations were found on fish or GPP response variables (Table 3). Karlsson and others (2009) found strong relationships between light climate and fish community production over a substantially larger gradient in air temperature, with high and similar fish production both in clear oligotrophic warm boreal and cold mountain lakes, suggesting that fish production may be less dependent on temperature within the narrower scope of relatively clear oligotrophic northern lakes.

\section{Fish Community Biomass and Production}

Fish community biomass and production were not related to $\mathrm{GPP}_{\text {whole }}$ and $\mathrm{GPP}_{\text {Benthic }}$ (Figure $3 \mathrm{~A}$, Table 3). Instead, benthic contribution to $\mathrm{GPP}_{\text {whole }}$ explained fish community biomass and production (Figure 3B, Table 3), which we argue highlights the important role of ontogeny for population biomass production. We base this conclusion on recent experimental and theoretical studies on the consequences of ontogenetic niche shifts in sizestructured populations, which have suggested that, with increasing proportion of adult resources (in this case benthic), fish population biomass increases even if total resource availability does not change (Persson and de Roos 2013; Reichstein and others 2015). In mountain lakes with salmonids, increasing relative contribution of benthic resources will reduce competition in the adult stage, with subsequent increases in total biomass and production. Theory further predicts that, in populations where adults are more limited by their resources than juveniles, an increase in productivity in juvenile resources will not cause an increase in population biomass. If anything, it will instead result in increased competition and reduced growth of adults with a subsequent decreased biomass of fish (de Roos and Persson 2013; Reichstein and others 2015). Hence, general theory for size-structured populations with ontogenetic niche shifts suggests that changes in productivity of a specific resource will affect fish biomass production differently depending on which stage-juvenile or adult-is more dependent on that specific resource. The stronger positive relationships of fish biomass and production to the benthic contribution to $\mathrm{GPP}_{\text {Whole, }}$ rather than to GPP Whole $_{\text {(Figure 3), fur- }}$ ther emphasize the importance of benthic primary production for adult fish and subsequently fish biomass production in clear oligotrophic lakes (cf. Karlsson and others 2009). Interestingly, these results also indicate that, independent of total lake productivity, the relative share of pelagic and benthic resource production for small juveniles and large adults is important for fish biomass production.

Ontogenetic niche shifts are rarely discrete in nature and depend on the relative profitability of the resources and mortality risks in each habitat (Werner and Gilliam 1984). A discrete separation of resources to either 'juvenile' or 'adult' is therefore not as strictly categorical as implied above. Both Arctic char and brown trout are able to feed on benthic invertebrates even at small sizes, and adults may also include zooplankton in their diets (Klemetsen and others 2003). However, at least four mechanisms may alone or in combination promote a continuous niche shift with increasing size in these species. First, gape limitation makes large invertebrate prey initially inaccessible for small individuals (Schmitt and Holbrook 1984; Sánchez-Hernández and others 2011). Second, the scaling of foraging capacity and metabolic demand 
with fish size causes small juveniles to be substantially more efficient foragers on zooplankton than adults (Jansen and others 2003; Byström and Andersson 2005). Third, the ability of large fish to exert interference competition and exclude small fish from the benthic resources (Hindar and Jonsson 1982; Kaspersson and others 2013) makes benthic invertebrates more exclusive to large fish. Finally, predation risk may cause juveniles to avoid the structurally homogenous soft bottom benthic habitats (Magnhagen and Borcherding 2008), which is often the main habitat contributing to benthic primary production in clear water lakes (Ask and others 2009). Theoretical analysis further shows that, in reasonably broad parameter space, the population dynamics and demographical population effects of continuous ontogenetic niche shifts compared to a discrete shift is minor (de Roos and others 2002). Thus, the qualitative effects are likely to prevail without regard to whether the ontogenetic shift from one resource to the other is discrete or continuous.

\section{Species-Specific and Community Type Effects}

Although we above focused on the general effects and importance of primary production in the benthic habitat on fish community biomass and production, our results also highlight both species- and community-specific differences (that is, allopatric vs. sympatric) in response to variation in habitatspecific measures of primary production (Figure 4, Table 3).

We tested if an increased benthic contribution to whole lake GPP would benefit larger individuals more than small individuals, that is, to cause an increase in the ratio of specific growth rates for large $(300 \mathrm{~mm})$ and small fish $(150 \mathrm{~mm})$. Although there was no overall evidence when the two species were combined, we found that for brown trout the ratio of specific growth rates increased with increasing benthic proportion of $\mathrm{GPP}_{\text {whole }}$ (Figure 6). This was mainly driven by an increase in the specific growth of large brown trout rather than a decline in specific growth of small fish, consistent with theory (De Roos and Persson 2013). Based on life-history characteristics, the presence of such an effect should also be more evident for brown trout than it is for Arctic char, because especially larger brown trout need larger sized benthic resources to have high growth rates while Arctic char is the more efficient planktivore compared to brown trout (Hesthagen and others 1997; Jansen and others 2002). Nevertheless, our results indicate that benthic resource production was important also for larger Arctic char, as the maximum length of Arctic char increased similarly as it did for brown trout with an increasing benthic contribution to $\mathrm{GPP}_{\text {Whole }}$ (Figure 5), as well as with $\mathrm{GPP}_{\text {Benthic }}$ in sympatric populations.

Allopatric brown trout biomass and production were positively related to both $\mathrm{GPP}_{\text {Benthic }}$ and $\mathrm{GPP}_{\text {Whole }}$ due to the strong covariation between the two GPP estimates (Table 3). This covariation is not surprising because much of $\mathrm{GPP}_{\text {Whole }}$ is contributed by $\mathrm{GPP}_{\text {Benthic }}(79-95 \%)$. These responses in biomass and production were apparent in brown trout populations but not in Arctic char populations (Table 3). This may be related to species-specific foraging efficiency traits as Arctic char feed on zooplankton more efficiently even as adults compared to brown trout (Hesthagen and others 1997; Jansen and others 2002; Saksgård and Hesthagen 2004). However, our data set only included five allopatric Arctic char lakes. Thus, the lack of relationships here may also be explained by low statistical power.

In sympatric lakes, the population biomasses of brown trout were higher than for Arctic char and the difference increased with increasing $\mathrm{GPP}_{\text {Benthic }}$ (Figure 4D). Moreover, brown trout biomass and production in sympatric populations were similar to allopatric populations and showed similar responses to increasing $\mathrm{GPP}_{\text {Benthic }}$ (Figure 4). In contrast, Arctic char biomass and production were substantially lower in sympatric lakes than in allopatric lakes (Figure 4). Overall, our results from the sympatric lakes corroborate previous findings that Arctic char is more limited by interspecific competition from brown trout, while brown trout is more limited by intraspecific competition (Langeland and others 1991; Jansen and others 2002), as suggested by the clear positive population responses to increasing $\mathrm{GPP}_{\text {Benthic }}$ (Figure 4). The switch in maximum and mean size depending on community type (Figure 5) could reflect the ability of brown trout to exclude Arctic char from the littoral habitat. Specifically, in allopatric populations, Arctic char reach larger sizes than brown trout over the whole range of increased benthic proportions of $\mathrm{GPP}_{\text {whole, }}$ whereas in sympatric communities, brown trout reach sizes larger than the Arctic char over the range of benthic proportions of $\mathrm{GPP}_{\text {whole }}$ (Figure 5). Furthermore, brown trout reached larger maximum sizes in sympatric populations when compared to allopatric populations (Figure 5), which may be due to a positive effect on growth from predation on juvenile Arctic char (Persson and others 2007). Apart from a direct predation 

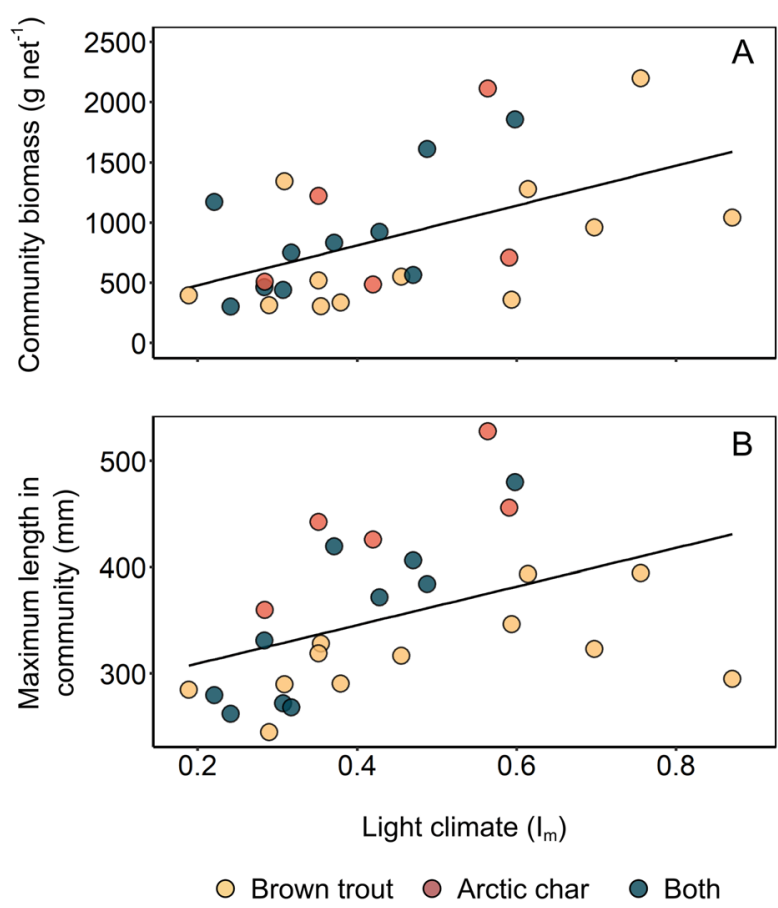

Figure 7. Fish community biomass $\mathbf{A}$ and maximum length $\mathbf{B}$ of fish in the lakes as a function of light climate $\left(I_{\mathrm{m}}\right)$. Brown trout (yellow) and Arctic char (red) represent the species in allopatric lakes while the category "both" represents sympatric lakes. Note that the largest fish in the sympatric lakes was in all cases a brown trout. Solid lines denote significant correlations $(p<0.05)$.

effect on growth, the resulting reduced interspecific competition from the consumption of Arctic char may potentially promote brown trout growth even further (Persson and others 2007).

At the individual level and independent of species, the benthic proportion of $\mathrm{GPP}_{\text {whole }}$ was strongly associated with fish size in both allopatric and sympatric populations. The maximum size of brown trout increased in both community types, and the maximum size of Arctic char increased in sympatric populations with the benthic proportion of GPP whole (Figure 5A, B). The mean size of both species increased over the range of benthic pro-

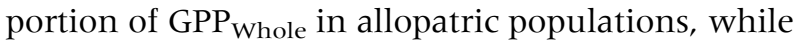
a tendency for mean size increase was evident for brown trout in sympatric populations (Figure 5C, D). Hence, the species-specific responses followed the theoretical predictions based on effects of ontogenetic asymmetry, development, and niche shifts, with stronger responses at both population and individual level when adults are relatively more efficient feeders on the benthic rather than on the pelagic resource (de Roos and Persson 2013; Reichstein and others 2015).
Significant associations of temperature with fish population (Table 3) or individual response variables were only found on Arctic char in sympatric lakes. When in sympatry with brown trout, Arctic char are commonly excluded to a large extent from the littoral habitats and are thereby forced to rely more on pelagic resource production (Langeland and others 1991; Hesthagen and others 1997). As pelagic primary production may be more responsive to temperature variation than benthic production (Hamdan and others 2021), a tentative explanation behind this effect may be that, in warmer lakes, pelagic primary production is stimulated by warmer temperatures with positive effect on the small pelagic feeding Arctic char in sympatric lakes. However, we cannot test for the effect of temperature on habitat-specific primary production due to our approach and the assumptions behind the model output of each habitats contribution to GPP whole. If the pelagic production is more dependent on temperature than the benthic production, any increase in pelagic GPP with temperature would only be reflected into our $\mathrm{GPP}_{\text {whole }}$ measurement and not assigned directly to the pelagic habitat in our temperature-independent model estimates of proportion of $\mathrm{GPP}_{\text {Whole }}$.

\section{Estimates of whole lake and habitat- specific GPP and assumptions and implications for fish resource production}

Our study is, to our knowledge, the first study that relates fish biomass and GPP in lakes to in situ continuous measures of levels of GPP over large gradients in lake morphology and water color. Our measures of whole ecosystem GPP based on continuous free-water diel oxygen concentration measures are the daily estimates weighted by model uncertainty (see methods and Appendix). This approach may introduce a bias in the estimates towards sunny clear sky days because this is when the model tend to perform best, which in turn would lead to an overestimation of GPP whole (Rose and others 2014). Although possibly counterintuitive, this effect would reduce the between-lake differences due to variation in weather conditions. We sampled the lakes in two consecutive years and over a large geographical range. So, in effect, by allowing for larger influence on our average estimates from clear sky days, we reduce the undesired dependency of between-site and temporal variations in weather at the cost of overestimating production over the season. We argue that this approach provides more accurate estimates of the 
variation in GPP between lakes compared to the situation where all days are given equal weight regardless of weather.

We further implicitly assume that the production of algae transfers to the production of primary consumers (fish resource) to the same extent in both habitats, that is, first level trophic transfer efficiencies are equal in both habitats. However, Vadeboncoeur and Power (2017) hypothesize that the trophic transfer efficiency may be higher in benthic habitats because of potentially lower consumption costs for grazers on benthic algae compared to zooplankton feeding on pelagic phytoplankton. Still, as our analysis in this study relies on between-lakes comparisons in estimates obtained by the same approach, the suggested mechanisms behind the results obtained and conclusions drawn would still hold even with asymmetric transfer efficiencies to primary consumers.

\section{Conclusions}

Our results show that increasing benthic proportion of $\mathrm{GPP}_{\text {whole }}$ correlates with both higher fish community biomass and yearly fish production. Our results also indicate that lakes with high fish biomass production are also lakes with higher specific growth rates of large relative to small fish and/or with larger sized individuals. Both of these results are in line with theoretical predictions based on population effects of ontogenetic asymmetry, development, and niche shifts when large adults have access to more resources than juveniles. Hence, our results highlight the importance of such interactions and suggest that, in oligotrophic high latitude lakes, the relative contribution of the benthic habitat to whole ecosystem GPP is more important for fish biomass production than the absolute levels of whole ecosystem primary production. Our results, therefore, convey the importance of stage-specific resource availability in these ecosystems and offers mechanistic details grounded in ecological theory that previous studies relating fish production to measures of light climate lack.

\section{Implications for Management}

Our study contributes to understanding the mechanisms behind variation in fish size and production in oligotrophic lakes, specifically linking the importance of light climate to the theory of the asymmetric effects of ontogenetic niche shifts and habitat-specific resource production. Mountain lakes are numerous and often remote, making efficient monitoring difficult and increasing the cost of active management and decision-making based on knowledge of the natural population structure and abundance of the fish populations. At the same time, because fish population responses to harvesting or habitat alterations are expected to differ depending on which stage, juveniles or adults are the most limited by their respective main resource (Reichstein and others 2015), information on expected lake-specific fish size structure and production would assist in diversifying and better targeting of possible management actions to lakes where the benefits are highest. Moreover, our study suggests that the predictive power of light climate, despite the lack of direct mechanistic understanding, for fish size and biomass can be a useful proxy for likely population size structure and abundance (Figure 7). Although estimating a lake's light climate still requires information on water color and lake bathymetry such information are substantially less costly to obtain than information of fish population demographics attained by large scale field surveys of fish abundance. We foresee that remote sensing, particularly airborne LIDAR techniques for lake bathymetry (Paine and others 2013), and satellite image analysis for water color (Al-Kharusi and others 2020) are likely methods that can be used even now or in the near future to provide cost-efficient information on light climate in lakes. We therefore suggest that, in lakes in regions where data gathering is otherwise costly and difficult to obtain management agencies can use measures of light climate as cost-efficient proxies to obtain measures of natural fish population structure and biomass production.

\section{ACKNOWLEDGEMENTS}

We thank Shuntaro Koizumi, André M de Roos, and James Elser for valuable comments on the paper. We also thank Petter Johansson, Erik Geibrink, Bror Holmgren, Karl Heuchel, and Pia Bartels for invaluable assistance during field and lab work. The study was funded by Knut and Alice Wallenbergs foundation (Grant Number: 2016.0083) and FORMAS (Grant Number: FR-2015/00723).

\section{FUNDING}

Open access funding provided by Umeå University. 


\section{OPEN ACCESS}

This article is licensed under a Creative Commons Attribution 4.0 International License, which permits use, sharing, adaptation, distribution and reproduction in any medium or format, as long as you give appropriate credit to the original author(s) and the source, provide a link to the Creative Commons licence, and indicate if changes were made. The images or other third party material in this article are included in the article's Creative Commons licence, unless indicated otherwise in a credit line to the material. If material is not included in the article's Creative Commons licence and your intended use is not permitted by statutory regulation or exceeds the permitted use, you will need to obtain permission directly from the copyright holder. To view a copy of this licence, visit $h$ ttp://creativecommons.org/licenses/by/4.0/.

\section{REFERENCES}

Aljetlawi AA, Leonardsson K. 2002. Size-dependent competitive ability in a deposit-feeding amphipod, Monoporeia affinis. Oikos 97:31-44.

Al-Kharusi ES, Tenenbaum DE, Abdi AM, Kutser T, Karlsson J, Bergström A-K, Berggren M. 2020. Large-scale retrieval of coloured dissolved organic matter in northern lakes using sentinel-2 data. Remote Sens 12:157.

Ask J, Karlsson J, Persson L, Ask P, Byström P, Jansson M. 2009. Whole-lake estimates of carbon flux through algae and bacteria in benthic and pelagic habitats of clear-water lakes. Ecology 90:1923-1932.

Bergström AK, Faithfull C, Karlsson D, Karlsson J. 2013. Nitrogen deposition and warming-effects on phytoplankton nutrient limitation in subarctic lakes. Glob Change Biol 19:2557-2568.

Byström P, Andersson J. 2005. Size-dependent foraging capacities and intercohort competition in an ontogenetic omnivore (Arctic char). Oikos 110:523-536.

Craig N, Jones SE, Weidel BC, Solomon CT. 2017. Life history constraints explain negative relationship between fish productivity and dissolved organic carbon in lakes. Ecol Evol 7:6201-6209.

Devlin SP, Vander Zanden MJ, Vadeboncoeur Y. 2016. Littoralbenthic primary production estimates: sensitivity to simplifications with respect to periphyton productivity and basin morphometry. Limnol Oceanogr Methods 14:138-149.

de Roos AM, Leonardsson K, Persson L, Mittelbach GG. 2002. Ontogenetic Niche Shifts and flexible behavior in size-structured populations. Ecol Monogr 72:271-292.

de Roos AM, Persson L. 2013. Population and community ecology of ontogenetic development. Princeton: Princeton University Press.

Downing JA. 2014. Productivity of freshwater ecosystems and climate change. In: Freedman B, Ed. Global environmental change. Handbook of global environmental pollution. Vol. 1. Dordrecht: Springer. pp 221-9.
Eloranta AP, Kahilainen KK, Jones RI. 2010. Seasonal and ontogenetic shifts in the diet of Arctic charr Salvelinus alpinus in a subarctic lake. J Fish Biol 77:80-97.

Eloranta AP, Knudsen R, Amundsen P-A. 2013. Niche segregation of coexisting Arctic charr (Salvelinus alpinus) and brown trout (Salmo trutta) constrains food web coupling in subarctic lakes: decoupling of food webs in subarctic lakes. Freshw Biol 58:207-221.

Forseth T, Ugedal O, Jonsson B. 1994. The energy budget, Niche shift, reproduction and growth in a population of Arctic charr, Salvelinus alpinus. J Anim Ecol 63:116.

Hamdan M, Byström P, Hotchkiss ER, Al-Haidarey MJ, Karlsson J. 2021. An experimental test of climate change effects in northern lakes: increasing allochthonous organic matter and warming alters autumn primary production. Freshw Biol 66(5):815-825.

Hanson PC, Carpenter SR, Kimura N, Wu C, Cornelius SP, Kratz TK. 2008. Evaluation of metabolism models for free-water oxygen methods in lakes. Limnol Oceanogr Methods 6:454465

Hesthagen T, Jonsson B, Ugedal O, Forseth T. 1997. Habitat use and life history of brown trout (Salmo trutta) and Arctic charr (Salvelinus alpinus) in some low acidity lakes in central Norway. Hydrobiologia 348:113-126.

Hindar K, Jonsson B. 1982. Habitat and food segregation of dwarf and normal Arctic charr (Salvelinus alpinus) from Vangsvatnet Lake, western Norway (Lonavatnet Lake). Can J Fish Aquat Sci 39:1030-1945.

Huss M, Lindmark M, Jacobson P, van Dorst RM, Gårdmark A. 2019. Experimental evidence of gradual size-dependent shifts in body size and growth of fish in response to warming. Glob Change Biol 25:2285-2295.

Jansen PA, Finstad AG, Langeland A. 2003. Size-scaling of zooplankton foraging in Arctic charr. J Fish Biol 62:860-870.

Jansen PA, Slettvold H, Finstad AG, Langeland A. 2002. Niche segregation between Arctic char (Salvelinus alpinus) and brown trout (Salmo trutta): an experimental study of mechanisms. Can J Fish Aquat Sci 59:6-11.

Kahilainen K, Lehtonen H. 2002. Brown trout (Salmo trutta L.) and Arctic charr (Salvelinus alpinus (L.)) as predators on three sympatric whitefish (Coregonus lavaretus (L.)) forms in the subarctic Lake Muddusjärvi: whitefish predation by brown trout and Arctic charr. Ecol Freshw Fish 11:158-167.

Karlsson J, Byström P. 2005. Littoral energy mobilization dominates energy supply for top consumers in subarctic lakes. Limnol Oceanogr 50:538-543.

Karlsson J, Byström P, Ask J, Ask P, Persson L, Jansson M. 2009. Light limitation of nutrient-poor lake ecosystems. Nature 460:506-509.

Kaspersson R, Sundström F, Bohlin T, Johnsson JI. 2013. Modes of competition: adding and removing brown trout in the wild to understand the mechanisms of density-dependence. PLoS ONE 8(5):e62517.

Klemetsen A, Amundsen P, Dempson J, Jonsson B, Jonsson N, O'Connel M, Mortensen E. 2003. Atlantic salmon Salmo salar L., brown trout Salmo trutta L. and Arctic charr Salvelinus alpinus ( L.): a review of aspects of their life histories. Ecol Freshw Fish 155-166 702.

Langeland A, L'Abee-Lund JH, Jonsson B, Jonsson N. 1991. Resource partitioning and Niche shift in Arctic Charr Salvelinus alpinus and brown trout Salmo trutta. J Anim Ecol 60:895. 
Lindmark M, Huss M, Ohlberger J, Gårdmark A. 2018. Temperature-dependent body size effects determine population responses to climate warming. Ecol Lett 21(2):181-189.

Lundberg S, Persson L. 1993. Optimal body size and resource density. J Theor Biol 164:163-180.

Magnhagen C, Borcherding J. 2008. Risk-taking behaviour in foraging perch: does predation pressure influence age-specific boldness? Anim Behav 75:509-517.

Morrissey-McCaffrey E, Shephard S, Kelly FL, Kelly-Quinn M. 2018. Non-native species and lake warming negatively affect Arctic char Salvelinus alpinus abundance; deep thermal refugia facilitate co-existence. J Fish Biol 94(1):5-16.

O'Connor MI, Piehler MF, Leech DM, Anton A, Bruno JF. 2009. Warming and resource availability shift food web structure and metabolism. PLoS Biol 7(8):e1000178.

Paine JG, Andrews JR, Saylam K, Tremblay TA, Averett AR, Caudle TL, Meyer T, Young MH. 2013. Airborne lidar on the Alaskan North Slope: wetlands mapping, lake volumes, and permafrost features. Lead Edge 32:798-805.

Persson L. 1985. Assymmetrical competition: Are larger animals competitively superior? Am Nat 126:261-266.

Persson L, Amundsen P, Klemetsen A, Knudsen R, Primicerio R. 2007. Culling prey promotes predator recovery-alternative states in a whole-lake experiment. Science 316(5832):17431746.

Persson L, Greenberg LA. 1990. Optimal foraging and habitat shift in perch (Perca fluviatilis) in a resource gradient. Ecology 71:1699-1713.

Persson L, Leonardsson K, de Roos AM, Christensen B. 1998. Ontogenetic scaling of foraging rates and the dynamics of a size-structured consumer-resource model. Theor Popul Biol 54(3):270-293.

Persson L, de Roos AM. 2013. Symmetry breaking in ecological systems through different energy efficiencies of juveniles and adults. Ecology 94:1487-1498.

R Core Team. 2021. R. Vienna, Austria. https://www.R-project. org/.

Reichstein B, Persson L, de Roos AM. 2015. Ontogenetic asymmetry modulates population biomass production and response to harvest. Nat Commun 6:6441.

Rose KC, Winslow LA, Read JS, Read EK, Solomon CT, Adrian R, Hanson PC. 2014. Improving the precision of lake ecosystem metabolism estimates by identifying predictors of model uncertainty. Limnol Oceanogr Methods 12:303-312.

Saksgård R, Hesthagen T. 2004. A 14-year study of habitat use and diet of brown trout (Salmo trutta) and Arctic charr (Salvelinus alpinus) in Lake Atnsjøen, a subalpine Norwegian lake. Hydrobiologia 521:187-199.

Sánchez-Hernández J, Vieira-Lanero R, Servia MJ, Cobo F. 2011. First feeding diet of young brown trout fry in a temperate area: disentangling constraints and food selection. Hydrobiologia 663:109-119.

Sánchez-Hernández J. 2020. Drivers of piscivory in a globally distributed aquatic predator (brown trout): a meta-analysis. Sci Rep 10:11258. https://doi.org/10.1038/s41598-020-68207 -8 .

Schmitt RJ, Holbrook SJ. 1984. Gape-limitation, foraging tactics and prey size selectivity of two microcarnivorous species of fish. Oecologia 63:6-12.
Seekell DA, Lapierre J-F, Ask J, Bergström A-K, Deininger A, Rodríguez P, Karlsson J. 2015. The influence of dissolved organic carbon on primary production in northern lakes. Limnol Oceanogr 60:1276-1285.

Seekell D, Cael S, Norman S, Byström P. 2021. Patterns and Variation of Littoral Habitat Size Among Lakes. Geophysical Research Letters. 48:20.

Solomon CT, Bruesewitz DA, Richardson DC, Rose KC, Van de Bogert MC, Hanson PC, Kratz TK, Larget B, Adrian R, Babin BL, Chiu C-Y, Hamilton DP, Gaiser EE, Hendricks S, Istvànovics V, Laas A, O'Donnell DM, Pace ML, Ryder E, Staehr PA, Torgersen T, Vanni MJ, Weathers KC, Zhu G. 2013. Ecosystem respiration: drivers of daily variability and background respiration in lakes around the globe. Limnol Oceanogr 58:849-866.

Staehr PA, Bade D, Koch GR, Williamson C, Hanson P, Cole JJ, Kratz T. 2010. Lake metabolism and the diel oxygen technique: state of the science. Limnol Oceanogr Methods 8:628644

Svenning MA, Hanssen ØK, Elliott JM. 2015. Changes in the density and growth of brown trout (Salmo trutta) after intensive removal of sympatric Arctic charr (Salvelinus alpinus) in the sub-Arctic lake Møkkelandsvatn, Norway. Ecol Freshw Fish 24:591-599.

Swedish-standards-institute. 2015. Water quality-sampling of fish with multi-mesh gillnets. Swedish standard SS-EN 14757:2015.

Vadeboncoeur Y, Peterson G, Vander Zanden MJ, Kalff J. 2008. Benthic algal production across lake size gradients: interactions among morphometry, nutrients, and light. Ecology 89:2542-2552.

Vadeboncoeur Y, Power ME. 2017. Attached algae: the cryptic base of inverted trophic pyramids in freshwaters. Annu Rev Ecol Evol Syst 48:255-279.

Vainikka A, Jakubavičiūte E, Hyvärinen P. 2017. Synchronous decline of three morphologically distinct whitefish (Coregonus lavaretus) stocks in Lake Oulujärvi with concurrent changes in the fish community. Fish Res 196:34-46.

van Dorst R, Gårdmark A, Svanbäck R, Beier U, Weyhenmeyer G, Huss M. 2019. Warmer and browner waters decrease fish biomass production. Glob Change Biol 25:1395-1408.

Vander Zanden MJ, Vadeboncoeur Y. 2002. Fishes as integrators of benthic and pelagic food webs in lakes. Ecology 83:21522161.

Vander Zanden MJ, Vadeboncoeur Y, Chandra S. 2011. Fish Reliance on littoral-benthic resources and the distribution of primary production in lakes. Ecosystems 14:894-903.

Werner EE. 1994. Ontogenetic Scaling of Competitive Relations: Size-Dependent Effects and Responses in Two Anuran Larvae. Ecology 75:1, 197-213.

Werner EE, Gilliam JF. 1984. The ontogenetic Niche and species interactions in size-structured populations. Annu Rev Ecol Evol Syst 15:393-425.

Westin L, Aneer G. 1987. Locomotor activity patterns of nineteen fish and five crustacean species from the Baltic Sea Environ Biol Fish 20:49-65. 